\title{
Broad-sense Heritability and Stability Analysis of Brown Patch Resistance in Tall Fescue
}

\author{
Jonathan M. Bokmeyer ${ }^{1}$, Stacy A. Bonos, and William A. Meyer \\ Department of Plant Biology and Pathology, Rutgers, The State University of \\ New Jersey, 59 Dudley Road, Foran Hall, New Brunswick, NJ 08901
}

Additional index words. Festuca arundinacea, Rhizoctonia solani, genotype $\times$ environment

\begin{abstract}
Brown patch, caused by Rhizoctonia solani Kühn, is a devastating disease of tall fescue (Festuca arundinacea Schreb.). Developing genetic resistance is a viable long-term control strategy; however, the genetic mechanism of brown patch resistance in tall fescue is not known. The objectives of this study were to determine the broad-sense heritability and stability analysis of brown patch resistance in tall fescue. To complete these objectives, 230 tall fescue genotypes were arranged in a randomized complete block design with six clonal replications at two locations and evaluated for brown patch resistance over 2 years. Two isolates of $R$. solani were used to inoculate both field trials at a rate of $0.8 \mathrm{~g} \cdot \mathrm{m}^{-2}$ of prepared inoculum. The lack of complete resistance and the observation of a continuous distribution of phenotypes suggest that brown patch resistance is quantitatively inherited. The broad-sense heritability estimates $(0.25$ on a single plant basis and 0.74 on 12-plant clonal mean basis) indicate that resistance is influenced by the genotype and also illustrate the importance of replication in selecting for brown patch resistance in tall fescue. Stability analysis resulted in the identification of tall fescue genotypes that were stable over multiple environments for brown patch resistance.
\end{abstract}

Tall fescue (Festuca arundinacea Schreb.) is a cool-season turfgrass that is commonly used throughout the North American transition zone for residential lawns, athletic fields, golf course roughs, and lower maintenance parks and recreation areas (Beard, 1973). The most devastating disease of tall fescue is brown patch caused by Rhizoctonia solani Kühn. Brown patch can reduce the overall quality and aesthetics of the turf stand (Couch, 1985; Martin and Lucas, 1984) and reduce stand density when disease is severe.

Current control options to reduce disease severity include restricting the amount of nitrogen applied to the turf (Burpee, 1995), limiting the duration of leaf wetness (Fidanza et al., 1996; Gross et al., 1998), and, in some cases, the use of fungicides (Fidanza and Dernoeden, 1996; Smiley et al., 2005). The development of resistant cultivars would provide the most practical, long-term approach to controlling brown patch. It has been documented by several authors that significant differences in susceptibility to brown patch exist among tall fescue cultivars (Burpee, 1995; Giesler et al., 1996; Green et al., 1999).

Currently, the disease resistance mechanism of brown patch resistance in tall fescue is not fully understood. Green et al. (1999) postulated that disease severity was a function of variation in leaf width and concluded

Received for publication 28 Oct. 2008. Accepted for publication 24 Jan. 2009.

New Jersey Experiment Station Publication No. D-12180-09-08.

${ }^{1}$ To whom reprint requests should be addressed; e-mail bokmeyer@eden.rutgers.edu. that the wider leaf blades of the cultivar Kentucky 31 had less disease than the finerleafed cultivar Mojave. Giesler et al. (1996) evaluated resistance of tall fescue to brown patch by comparing dense versus open canopies and found that a higher canopy density increased disease severity. They reported that a higher canopy density compared with a lower canopy density created a more favorable environment for brown patch by increasing relative humidity and leaf wetness. It was also suggested that hyphal expansion occurs more readily in dense canopies as a result of the close proximity of leaf blades. These studies have shed light on some of the physiological and environmental factors that play a role in resistance, but they did not address potential genetic factors that may be involved. To develop new cultivars with improved resistance, the genetic factors of brown patch resistance must be determined.

Plant breeders use heritability estimates to determine the influence of the environmental and genetic factors affecting the trait of interest and what selection procedure should be implemented to make improvements. Heritability can be defined as the proportion of the observed variation in a progeny that is inherited (Poehlman and Sleper, 1995). The extent to which replicated testing is required for selection will depend on the heritability estimate (Nyquist, 1991). Broad-sense heritability is the ratio of total genetic (additive, dominance, and epistatic) variance to phenotypic variance (Dudley and Moll, 1969). This estimate gives plant breeders an understanding to what extent a trait is influenced by the genotype as opposed to the environment.
Burton and Devane (1953) used replicated clones of tall fescue to determine broad-sense heritability of several plant characteristics on a single-plant basis as well as on an entry mean basis. This method has been used by Bonos et al. (2003) to determine the broadsense heritability estimate of dollar spot (caused by the fungus Sclerotinia homoeocarpa F.T. Bennet) resistance in creeping bentgrass (Agrostis stolonifera L.). This technique was used in this study to determine the broad-sense heritability estimate of brown patch resistance in tall fescue.

Along with heritability estimates, understanding the magnitude of genotype-by-environment $(\mathrm{G} \times \mathrm{E})$ interaction of the trait being studied is critical in developing an effective breeding program. The larger the $\mathrm{G} \times \mathrm{E}$ interaction, the less correlation there is between the genotype and the phenotype, which reduces the effectiveness of selection (Comstock and Moll, 1963). Stability analysis is a method to evaluate the performance of genotypes over multiple years and locations. By identifying stable genotypes in preliminary evaluations, those that show a minimum interaction with the environment will lead to an increase in the number of stable genotypes used in advanced testing (Eberhart and Russell, 1966).

There are several definitions of stability that can be found throughout the literature. Authors have classified a genotype as stable if the response of the genotype over several environments was equivalent to that of the mean response of all genotypes in the trial (Shukla, 1972), equivalent to the best performing genotype in each environment (Lin and Binns, 1988), or significantly greater than the mean response of genotypes at each location (Casler et al., 2001). Other authors have used ranking systems to determine if a genotype is stable over multiple environments (Fox et al., 1990; Kang and Pham, 1991). Each stability statistic interprets the $\mathrm{G} \times \mathrm{E}$ interactions differently; therefore, it is up to the plant breeder to determine what method will provide the most relevant information to accomplish their breeding objectives.

The objectives of this study were to 1) determine broad-sense heritability of brown patch resistance of 230 tall fescue genotypes; and 2) determine the stability of resistance to brown patch.

\section{Materials and Methods}

Field trials. Two hundred thirty tall fescue genotypes were selected for evaluation in this study. The genotypes were randomly selected from plants growing at the Rutgers Plant Biology and Pathology Research and Extension Farm in Freehold, NJ, and consisted of experimental breeding material and germplasm recently collected from Europe. In the summer of 2004, a single tiller was removed from each of the 230 genotypes. Each tiller was then transplanted into a $5.1 \times$ 5.1-cm cell filled with BX potting media (Pro-Mix HP; K.C. Shafer, York, PA) and placed in a greenhouse for optimum growing 
conditions. In the fall of 2004, each genotype had increased to a sufficient size and was then divided into 12 separate vegetative replications remaining under greenhouse conditions through the fall and winter.

In April 2005, field studies were established at two locations. Site 1 was located at the Horticultural Research Farm II in North Brunswick, NJ, and Site 2 was located at the Rutgers Plant Biology and Pathology Research and Extension Farm in Freehold, NJ. The field trial at Site 1 was located in a field bordered on the eastern side by a row of trees and a wood line on the southern side. The soil type was a Nixon loam (fine-loamy, mixed, mesic Typic Hapludult). The field trial at Site 2 was located in an open field with no physical barriers within close proximity; the soil type was a Freehold sandyloam (fine-loamy, mixed, active, mesic Aquic Hapludult). Each field experiment was arranged in a randomized complete block design with six replications. To prepare each site, the existing turf (Perennial ryegrass Lolium perenne L.) was sprayed with glyphosate in the fall of 2004 and the dead plant material was not removed from the field before transplanting. The plants were transplanted into the field $31 \mathrm{~cm}$ apart. Plants at both sites were mowed two times per week during the growing season at a height of 6.4 $\mathrm{cm}$ and each experimental turf area received $\approx 14 \mathrm{~g} \cdot \mathrm{m}^{-2} \mathrm{~N}$ annually in 2005 and 2006 .

Inoculation method. Two isolates of $R$. solani were used as inoculum for both field studies. Both isolates were collected from Agrostis species growing at The Valentine Turfgrass Research Center, The Pennsylvania State University, University Park, PA. Inoculum was prepared by growing the $R$. solani isolates on sterilized Kentucky bluegrass seeds following the method described by Bonos et al. (2003). Inoculum of both isolates was mixed together in equal proportions and then placed in a drop spreader and applied at a rate of $0.8 \mathrm{~g} \cdot \mathrm{m}^{-2}$. To ensure favorable conditions for disease development, light irrigation was applied immediately after inoculation. To encourage growth and development of the pathogen, light irrigation was periodically applied in the afternoon during the course of the study. Assessment of brown patch disease severity was made in July and August in 2005 and 2006 using a 1 to 9 scale; 9 represented $0 \%$ to $5 \%$ diseased turf, 8 represented $5 \%$ to $15 \%$ diseased turf, 7 represented $15 \%$ to $30 \%$ diseased turf, 6 represented $30 \%$ to $45 \%$ diseased turf, 5 represented $45 \%$ to $55 \%$ diseased turf, 4 represented $55 \%$ to $70 \%$ diseased turf, 3 represented $70 \%$ to $85 \%$ diseased turf, 2 represented $85 \%$ to $95 \%$ diseased turf, and 1 represented $95 \%$ to $100 \%$ diseased turf. Because there has been no report of completely brown patch-resistant genotypes of tall fescue, levels of resistance and susceptibility were defined for this study using visual analysis. Based on visual analysis, an acceptable level of disease was $30 \%$ or less; any clone below this threshold was designated as resistant. An unacceptable level of disease was $50 \%$ or greater and any clone above this threshold was designated as susceptible.

Statistical analysis. All data analysis was conducted on percent disease using the average of the rating dates from each year. Brown patch disease data collected from the two locations over 2 years were subject to analysis of variance. The analysis of variance was generated by PROC GLM (SAS Institute, Cary, NC) as a result of an unbalanced data set. Broad-sense heritability estimates were determined from restricted maximum likelihood variance and covariance components using the random model PROC MIXED (SAS Institute). All effects were considered random because locations were not chosen with respect to specific ecological properties, years were not chosen with respect to expected climatic conditions (Gordon et al., 1972), and no information on disease resistance of tall fescue clones was known before the initiation of the study. Heritability was calculated on a clonal mean $(\mathrm{Hc})$ basis as well as on a single-plant basis (Hsp). The formulas are as follows:

$$
\begin{gathered}
\mathrm{Hc}=\sigma_{\mathrm{c}}^{2} /\left(\sigma_{\mathrm{c}}^{2}+\sigma_{\mathrm{cy}}^{2} / \mathrm{y}+\sigma_{\mathrm{c} 1}^{2} / 1\right. \\
\left.+\sigma_{\mathrm{cr}(1)}^{2} / \mathrm{r} 1+\sigma_{\mathrm{cy} 1}^{2} / 1 \mathrm{y}+\sigma_{\mathrm{e}}^{2} / \mathrm{r} 1 \mathrm{y}\right) \\
\mathrm{Hsp}= \\
\sigma_{\mathrm{c}}^{2} /\left(\sigma_{\mathrm{c}}^{2}+\sigma_{\mathrm{cy}}^{2}+\sigma_{\mathrm{c} 1}^{2}\right. \\
\left.+\sigma_{\mathrm{cr}(1)}^{2}+\sigma_{\mathrm{cy} 1}^{2}+\sigma_{\mathrm{e}}^{2}\right)
\end{gathered}
$$

where $\sigma_{\mathrm{c}}^{2}=$ the total genetic variance of clones, $\sigma_{\text {cy }}^{2}=$ clone $\times$ year variance, $\sigma_{\mathrm{cl}}^{2}=$ clone $\times$ location variance, $\sigma_{\mathrm{cr}(1)}^{2}=$ clone $\times$ replication within location variance, $\sigma_{\text {cyl }}^{2}=$ clone $\times$ year $\times$ location variance, and $\sigma_{\mathrm{e}}^{2}=$ experimental error (clone $\times$ year $\times$ replication within location). Letters in the denominator refer to the number of replications (six), replications (locations) (12) locations (two), and years (two) (Poehlman and Sleper, 1995).

Stability analysis was conducted to determine the response of each clone across environments. The method described subsequently is similar to the analysis conducted by Casler et al. (2001) and Bonos et al. (2004a). For this analysis, each location in each year was considered a separate environment. For each environment, the clone means were computed and converted into a deviation from the location mean using the formula $x_{i j}=X_{i j}-M_{j}$, where $X_{i j}=$ the observation of the $i$ th population at the $j$ th location and $M_{j}=$ mean of the $j$ th location (Casler et al., 2001). The least significant value (LSV) for $\alpha=0.05$ was computed using the formula $\mathrm{t} \alpha / 2 \mathrm{dfe}$ $\sqrt{ }\left[\left(\mathrm{MSe}^{*} 2\right) / \mathrm{r}\right]$, where $\mathrm{MSe}$ was determined from the error term for analysis of variance from each location and $r=$ number of replications. Negative deviations from the location mean indicated that a clone exhibited a lower than average percent brown patch disease severity for that environment. Positive deviations from the location mean indicated that a clone exhibited a higher than average percent brown patch disease severity for that environment. A clone was considered stable across environments if it had a deviation from the location mean significantly less than (stable-resistant) or greater than (stablesusceptible) the LSV for all locations.

\section{Results and Discussion}

Brown patch severity. Analysis of variance of percent brown patch disease among tall fescue clones over two locations and 2 years resulted in all major effects and clone $x$ environment interactions being significant (Table 1). Average percent brown patch disease severity in 2005 was $45 \%$ (Site 1) and $44 \%$ (Site 2 ). Disease averages decreased in 2006 to $41 \%$ (Site 1) and 34\% (Site 2). Differences in disease severity observed between locations can be attributed to different environmental conditions at each site. The field trial at Site 1 was bordered by trees and shrubs on the eastern and southern sides, which may have led to a decrease in air movement, possibly resulting in prolonged leaf wetness. This resulted in increased disease pressure as opposed to the field trial at Site 2 that was planted in an open field,

\begin{tabular}{|c|c|c|c|c|c|}
\hline Sources of variation & $\mathrm{df}$ & Means square & $\mathrm{F}$ value & $\mathrm{P}>\mathrm{F}$ & Variance component \\
\hline$\overline{\text { Year }}$ & 1 & $72,228.73$ & 603.33 & $<0.0001$ & \\
\hline Location & 1 & $21,171.47$ & 176.85 & $<0.0001$ & \\
\hline $\begin{array}{c}\text { Replications } \\
\text { (location) }\end{array}$ & 10 & $1,433.94$ & 11.98 & $<0.0001$ & \\
\hline Year $\times$ location & 1 & $12,768.01$ & 106.65 & $<0.0001$ & \\
\hline $\begin{array}{l}\text { Year } \times \text { replication } \\
\quad(\text { location })\end{array}$ & 10 & 923.19 & 7.71 & $<0.0001$ & \\
\hline Clone & 229 & $16,161.55$ & 13.5 & $<0.0001$ & 50.9711 \\
\hline Clone $\times$ year & 229 & 399.74 & 3.34 & $<0.0001$ & 8.1284 \\
\hline Clone $\times$ location & 229 & 229.18 & 1.91 & $<0.0001$ & 0.1384 \\
\hline Clone $\times$ replication (location) & 2,288 & 144.02 & 1.2 & $<0.0001$ & 0.8008 \\
\hline Clone $\times$ year $\times$ location & 229 & 202.88 & 1.69 & $<0.0001$ & 3.5307 \\
\hline $\begin{array}{l}\text { Error clone } \times \text { year } \times \text { replication } \\
\quad(\text { location })\end{array}$ & 2,245 & 119.72 & & & 5.1017 \\
\hline $\mathrm{Hc}^{\mathrm{z}}=0.74$ & & & & & \\
\hline $\mathrm{Hsp}=0.25$ & & & & & \\
\hline
\end{tabular}
allowing for ample air circulation. Significant

Table 1. Analysis of variance of brown patch disease severity of 230 tall fescue clones averaged over two locations and 2 years (2005 and 2006).

${ }^{\mathrm{z}} 95 \%$ confidence interval for 12-plant mean heritability $=0.70-0.78$. 
differences in disease severity over years may have been caused by fluctuation in relative humidity and rainfall events.

Significant differences in brown patch resistance were observed among the different tall fescue genotypes evaluated in this study with the average percent disease over two locations and 2 years ranging from $21 \%$ to $60 \%$ (Fig. 1). No discrete reaction classes of susceptibility or resistance were observed; rather, there was a continuous distribution of responses to brown patch (Fig. 1). Some clones displayed moderate levels of resistance across multiple environments but no clone exhibited complete resistance. The lack of complete resistance, the observation of a continuous distribution of phenotypes, and the high influence of the environment on disease severity suggests that brown patch resistance is quantitatively inherited (Poehlman and Sleper, 1995).

Broad-sense heritability. Although all clone $\times$ environment interactions were significant, the main effect of clone had the largest variance component, illustrating there is a genetic component to resistance (Table 1). By using clonal replications to calculate heritability and evaluating them over multiple years and locations, we are able to account for the significant clone $\times$ environment variance and remove it from the total genetic variance (Burton and Devane, 1953). If the clones were only evaluated in one location over 1 year, the heritability estimate would be biased upward because the underlying clone $\times$ environment variance would not be detected (Dudley and Moll, 1969).

The broad-sense heritability for tall fescue clones evaluated over 2 years and two locations was 0.74 , whereas on a single-plant basis, it was only 0.25 (Table 1 ). The broadsense heritability estimate based on clones was similar to Watkins et al. (2009), although they did not use replicated clones. This broad-sense heritability estimate is lower than what has been reported for turfgrass disease resistance to other fungal pathogens (Bonos et al., 2003, 2004b). The difference between estimates based on clonal and a single-plant basis illustrates the effect of the environment on brown patch resistance in tall fescue. Because there is a large environmental effect, replication is important to get a true estimate of the response of a particular clone (genotype) to brown patch disease. Environmental variation can be reduced by increasing clonal replications at each location. By doing this, clones exhibiting resistance among multiple environments will be identified. Based on the broad-sense heritability estimated here, the most efficient selection program for brown patch resistance would be on a replicated clonal basis over multiple years and environments. The broad-sense heritability based on a single plant basis was quite low (0.25), indicating that selection based on nonreplicated single plants in one environment would not be very efficient in improving brown patch resistance in tall fescue. Bonos et al. (2003) also reported a large difference between broad-sense heritability estimates for dollar spot resistance in creeping bentgrass based on a clonal basis versus singleplant basis; however, our single plant estimate was much lower $(0.25$ versus 0.51$)$. It is important to note that this broad-sense heritability estimate only pertains to these clones evaluated over these different environments. Because broad-sense heritability accounts for all genetic effects (additive, dominance, and epistatic), this should be the maximum heritability expected when selection is based on clonal replications.

Stability analysis. When stability was analyzed by comparing the mean of each clone at a particular location to the location mean, no clone was significantly different from all four location means. Twenty-four $(10 \%)$ of the clones had an overall percent disease of $30 \%$ or less over both years and locations. Of those resistant genotypes, five were significantly less than the LSV in three of the four environments and seven genotypes were significantly less than the LSV in two of the four environments (Table 2). Thirty-three $(14 \%)$ of the clones had an overall percent disease of $50 \%$ or greater over both years and locations. Of those susceptible clones, one clone was significantly greater than the LSV in

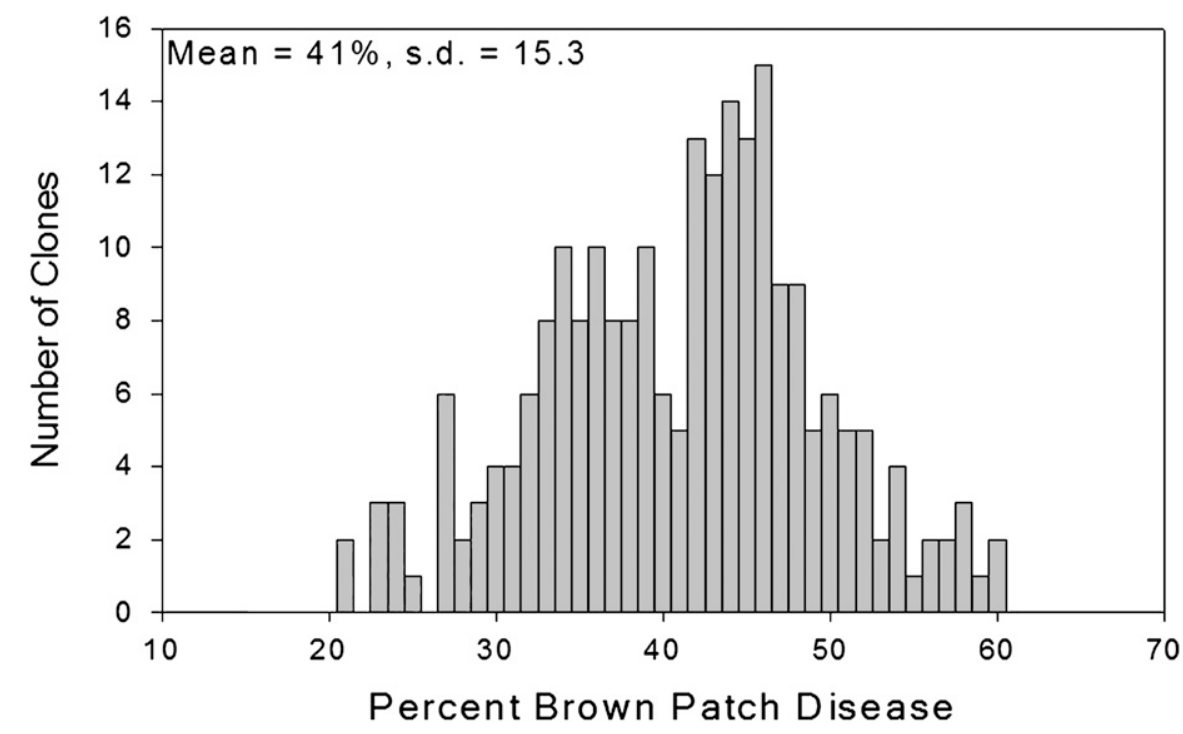

Fig. 1. Distribution of tall fescue clone responses to brown patch disease averaged over 2 years and two locations.

Table 2. Mean location deviations of tall fescue clones responses to brown patch disease across two locations and 2 years.

\begin{tabular}{|c|c|c|c|c|c|c|c|}
\hline & \multirow[b]{3}{*}{ Clone $^{\mathrm{z}}$} & \multirow[b]{3}{*}{ Designation $^{\mathrm{y}}$} & \multirow{3}{*}{$\begin{array}{c}\text { Brown patch } \\
\text { avg. }\end{array}$} & \multicolumn{2}{|c|}{ Freehold } & \multicolumn{2}{|c|}{ North Brunswick } \\
\hline & & & & 2005 & 2006 & 2005 & 2006 \\
\hline & & & & \multicolumn{4}{|c|}{ Deviation from location year means } \\
\hline 1 & 79 & $\mathrm{R}$ & 21 & $-27^{w}$ & -7 & -21 & -26 \\
\hline 2 & 193 & $\mathrm{R}$ & 21 & -20 & -9 & -29 & -23 \\
\hline 3 & 161 & $\mathrm{R}$ & 23 & -19 & -16 & -16 & -24 \\
\hline 4 & 224 & $\mathrm{R}$ & 23 & -24 & -3 & -21 & -24 \\
\hline 5 & 257 & $\mathrm{R}$ & 23 & -18 & -14 & -15 & -25 \\
\hline 6 & 175 & $\mathrm{R}$ & 24 & -25 & -10 & -17 & -17 \\
\hline 7 & 136 & $\mathrm{R}$ & 24 & -23 & -8 & -14 & -22 \\
\hline 8 & 256 & $\mathrm{R}$ & 24 & -8 & -17 & -19 & -24 \\
\hline 9 & 93 & $\mathrm{R}$ & 25 & -18 & -17 & -18 & -10 \\
\hline 10 & 148 & $\mathrm{R}$ & 27 & -5 & -11 & -14 & -28 \\
\hline 11 & 184 & $\mathrm{~S}$ & 56 & 19 & 13 & 11 & 17 \\
\hline 12 & 187 & $\mathrm{~S}$ & 56 & 13 & 14 & 17 & 17 \\
\hline 13 & 75 & $\mathrm{~S}$ & 57 & 16 & 18 & 16 & 14 \\
\hline 14 & 172 & $\mathrm{~S}$ & 57 & 11 & 10 & 22 & 20 \\
\hline 15 & 173 & $\mathrm{~S}$ & 58 & 20 & 10 & 23 & 15 \\
\hline 16 & 86 & S & 58 & 14 & 19 & 22 & 15 \\
\hline 17 & 44 & $\mathrm{~S}$ & 58 & 27 & 10 & 26 & 8 \\
\hline 18 & 249 & S & 59 & 12 & 38 & 3 & 19 \\
\hline 19 & 13 & $\mathrm{~S}$ & 60 & 21 & 12 & 19 & 20 \\
\hline 20 & 171 & $\mathrm{~S}$ & 60 & 23 & 20 & 12 & 21 \\
\hline \multicolumn{3}{|c|}{$\begin{array}{l}\text { Least significant difference }(0.05) \text { or } \\
\text { least significant value (LSV) }(0.05)\end{array}$} & 7.5 & 16.4 & 18.4 & 14.9 & 20.2 \\
\hline
\end{tabular}

${ }^{\text {zOnly }} 10$ clones representing resistant and susceptible classes are presented. Complete data set is available upon request.

${ }^{\mathrm{y}} \mathrm{R}=$ resistance $30 \%$ or less disease; $\mathrm{S}=$ susceptible $50 \%$ or greater disease.

xercent brown patch disease severity averaged across two locations and 2 years.

wBold numbers indicate significance above the LSv value. 
Table 3. Number of clones at each location that were significantly different from location mean using the least significant value for comparison $(P<0.05)$

\begin{tabular}{lrrrrr}
\hline & \multicolumn{2}{c}{ Freehold } & & \multicolumn{2}{c}{ North Brunswick } \\
\cline { 2 - 3 } \cline { 5 - 6 } & 2005 & 2006 & & 2005 & 2006 \\
\hline Lower & 11 & 1 & & 20 & 14 \\
No difference & 211 & 225 & & 196 & 210 \\
Higher & 8 & 4 & & 14 & 6 \\
\hline
\end{tabular}

three of the four environments and six clones were significantly greater than the LSV in two of the four environments (Table 2). Although no clone was stable across all four environments, all clones that were categorized as resistant had negative deviations over all locations; likewise, all clones categorized as susceptible had positive deviations over all locations. One explanation for the lack of stability over all four environments that was observed in this study was that in 2006 at Site 2 (Freehold), the mean percent disease for that location was only $34 \%$. This indicated that disease pressure was not as severe as the other three environments in which the clones were evaluated. When we summarized the number of clones at each location that were significantly above or below the location mean using the LSV (Table 3), the least amount of difference was observed at Freehold in 2006. A clone evaluated in this environment that performed better, but not significantly different from the location mean would still have to be considered stable for resistance because of the low location mean. The results from this stability analysis differ from that of other turfgrass pathosystems. For example, Bonos et al. (2004a) evaluated bentgrass clones for dollar spot resistance over multiple locations and years and were able to identify individual clones that were positively stable (resistant) or negatively stable (susceptible) across all environments. The lack of stability also demonstrates that brown patch disease severity is greatly influenced by the environment in which the plants are grown. Trials evaluating clones over multiple years and locations will be necessary to successfully identify superior genotypes for brown patch resistance to be used in breeding programs.

\section{Conclusions}

The findings of this study illustrate the large amount of genetic variation that is present among different tall fescue genotypes in response to brown patch. Moderate broadsense heritability estimates were observed indicating a strong environment influence on this trait. The significant interactions between clone and environment suggest that evaluation for resistance to brown patch should be conducted over multiple locations, years, and replications to identify genotypes that exhibit superior performance (Dudley and Moll, 1969). Stability analysis was able to identify genotypes of tall fescue that were stable for resistance over multiple environments. Therefore, these stable genotypes can be incorporated into a breeding program to improve brown patch resistance in tall fescue. The strong environmental effect and continuous distribution of responses to brown patch support the idea that brown patch resistance in tall fescue is quantitatively inherited. A phenotypic recurrent selection program using replicated genotypes should be an effective tool in breeding for resistance to brown patch in tall fescue.

\section{Literature Cited}

Beard, J.B. 1973. Turfgrass: Science and culture. Prentice-Hall, Englewood Cliffs, NJ.

Bonos, S.A., M.A. Casler, and W.A. Meyer. 2003. Inheritance of dollar spot resistance in creeping bentgrass. Crop Sci. 43:2189-2196.

Bonos, S.A., M.A. Casler, and W.A. Meyer. 2004a. Plant responses and characteristics associated with dollar spot resistance in creeping bentgrass. Crop Sci. 44:1763-1769.

Bonos, S.A., C. Kubik, B.B. Clarke, and W.A. Meyer. 2004b. Breeding perennial ryegrass for resistance to gray leaf spot. Crop Sci. 44:575580.

Burpee, L.L. 1995. Interactions among mowing height, nitrogen fertility, and cultivar affect the severity of Rhizoctonia blight of tall fescue. Plant Dis. 79:721-726.

Burton, G.W. and E.H. Devane. 1953. Estimating heritability in tall fescue (Festuca arundinacea) from replicated clonal material. Agron. J. 45:478-481.

Casler, M.D., K.P. Vogel, J.A. Balasko, J.D. Berdahl, D.A. Miller, J.L. Hansen, and J.O. Fritz. 2001. Latitudinal and longitudinal adaptation of smooth bromegrass populations. Crop Sci. 41:14561460.

Comstock, R.E. and R.H. Moll. 1963. Genotypeenvironment interactions, p. 164-196. In: Hanson, W.D., and H.F. Robinson (eds.). Statistical genetics and plant breeding. National Academy of Sciences-National Research Council Publication 982.

Couch, H.B. 1985. Turfgrass (several cultivated spp.). Plant Dis. 69:672-675.
Dudley, J.W. and R.H. Moll. 1969. Interpretation and use of estimates of heritability and genetic variance in plant breeding. Crop Sci. 9:257262.

Eberhart, S.A. and W.A. Russell. 1966. Stability parameters for comparing varieties. Crop Sci. 6:36-40.

Fidanza, M.A. and P.H. Dernoeden. 1996. Brown patch severity in perennial ryegrass as influenced by irrigation, fungicides, and fertilizers. Crop Sci. 36:1631-1638.

Fidanza, M.A., P.H. Dernoeden, and A.P. Grybauskas. 1996. Development and field validation of a brown patch warning model for perennial ryegrass turf. Phytopathology 86:385-390.

Fox, P.N., B. Skovmand, B.K. Thompson, H.-J. Braun, and R. Cormier. 1990. Yield and adaptation of hexaploid spring triticale. Euphytica 47:57-64.

Giesler, L.J., G.Y. Yuen, and G.L. Horst. 1996. The microclimate in tall fescue turf as affected by canopy density and its influence on brown patch disease. Plant Dis. 80:398-394.

Gordon, I.L., D.E. Byth, and L.N. Balaam. 1972. Variance of heritability ratios estimated from phenotypic variance components. Biometrics 28:401-415.

Green, D.E., II, L.L. Burpee, and K.L. Stevenson. 1999. Components of resistance to Rhizoctonia solani associated with two tall fescue cultivars. Plant Dis. 83:834-838.

Gross, M.K., J.B. Santini, I. Tikhonova, and R. Latin. 1998. The influence of temperature and leaf wetness duration on infection of perennial ryegrass by Rhizoctonia solani. Plant Dis. 82:10121016.

Kang, M.S. and H.N. Pham. 1991. Simultaneous selection for yielding and stable crop genotypes. Agron. J. 83:161-165.

Lin, C.S. and M.R. Binns. 1988. A superiority measure of cultivar performance for cultivar $\times$ location data. Can. J. Plant Sci. 63:193-198.

Martin, S.B. and L.T. Lucas. 1984. Characterization and pathogenicity of Rhizoctonia spp. and binucleate Rhizoctonia-like fungi from turfgrasses in North Carolina. Phytopathology 74:170-175.

Nyquist, W. 1991. Estimation of heritability and prediction of selection response in plant populations. Crit. Rev. Plant Sci. 10:235-322.

Poehlman, J.M. and D.A. Sleper. 1995. Breeding field crops. Iowa State University Press, Ames, IA.

Shukla, G.K. 1972. Some statistical aspects of partitioning genotype-environment components of variability. Heredity 29:237-245.

Smiley, R.W., P.H. Dernoeden, and B.B. Clarke. 2005. Compendium of turfgrass diseases. 3rd Ed. The American Phytopathological Society, St. Paul, MN.

Watkins, E., S.A. Bonos, and W.A. Meyer. 2009. Heritability of brown patch resistance in tall fescue. International Turfgrass Society Research Journal (in press). 